\title{
A General Equilibrium Analysis of Parental Leave Policies ${ }^{\dagger}$
}

\author{
Andrés Erosa \\ University of Toronto \\ Luisa Fuster \\ University of Toronto \\ Diego Restuccia
}

Federal Reserve Bank of Richmond and University of Toronto

August 2005

ABstract

An important feature of the U.S. labor market is that, even after controlling for measurable differences in education and experience, the average wage of women with children is 89 percent of the average wage of women without children. This "family gap" in wages accounts for almost half the gender gap in wages. Proponents of mandatory-leave policies argue that career interruptions associated with fertility have long-lasting effects on female employment and are costly in terms of human-capital losses for females. Despite the fact that mandatory leaves are widely applied in developed countries, their effects on the economy are not well understood. We develop and calibrate a general-equilibrium model of fertility and labor-market decisions to study the quantitative impact of such policies. We build on the Mortensen and Pissarides (1994) labor-market framework by introducing male and female workers, general and specific human-capital accumulation on the job, and temporary separations between the worker and a job. We find that: $(i)$ the loss of specific human capital accounts for a small fraction of the wage gaps and $(i i)$ mandatory-leave policies have substantial aggregate and redistributive effects on fertility, employment, and welfare. Interestingly, we find that the general-equilibrium effect of mandatory-leave policies is a reduction in the amount of time females spend at home with children.

Keywords: Parental leaves, fertility, specific human capital, temporary separations. JEL Classification: J2,J3.

${ }^{\dagger}$ We are grateful to Ig Horstmann for comments and suggestions. We also thank seminar participants at several universities and conferences. All remaining errors are our own. We acknowledge the financial support of the BBVA foundation. Erosa acknowledges the financial support of the Connaught Fund and the Social Sciences and Humanities Research Council of Canada (SSHRC). Fuster acknowledges the financial support of the Ministerio de Educación y Ciencia of Spain (grant SEJ2004-03149), the Connaught Fund, and SSHRC. Restuccia acknowledges the support of the Connaught Fund, the Institute for Policy Analysis at the University of Toronto and SSHRC. The views expressed in this paper are solely those of the authors and do not necessarily represent the views of the Federal Reserve Bank of Richmond or the Federal Reserve System. Contact Information: andres.erosa@utoronto.ca; luisa.fuster@utoronto.ca; and diego.restuccia@utoronto.ca. 


\section{Introduction}

Mandated parental-leave policies have been widely introduced in developed countries in the last two decades. These policies specify a minimum amount of time off work that a person is entitled to take in order to care for a newborn child or other family member, with dismissal prohibited during pregnancy, and with a job guarantee after the leave period.

The primary objective of mandatory temporary leaves is to promote greater female labor attachment by avoiding career interruptions due to childbirth. The impact of these policies in the economy have been the subject of substantial policy discussions in recent years (see, for instance, OECD, 1995). These discussions have been centered around the fact that in the U.S. labor market, the average wage of women with children is 89 percent of the average wage of women without children, even after adjusting for measurable differences in education and experience. Moreover, this gap accounts for almost half the wage gap between men and women (see Waldfogel, 1998a,b). Proponents of mandatory-leave entitlements argue that career interruptions by females due to childbirth are costly in terms of human capital losses. The presumption is that family policies may reduce the wage gap between women with children and those without children, by minimizing the loss of specific human capital (Waldfogel, 1998a). Moreover, it is also argued that these policies could reduce the wage gap between mothers with different skill levels since career interruptions for childbirth are more likely for females at the lower end of the skill distribution (Royalty, 1998).

Despite these arguments and the fact that mandatory parental-leave policies have been widely introduced in most developed countries (OECD, 1995), their effects on employment, 
wages, and fertility are far from being well understood (Blau and Khan, 1992). On the theoretical side, the effects of mandated leaves on the economy are not trivial. Mandated leaves may have a negative impact on female wages relative to those of males if they imply a direct or indirect cost for firms with redistributive effects within female types. Also, mandated leaves can be thought as a rigidity in the labor market with potential negative consequences on aggregate employment (see, for instance, Ljungqvist and Sargent, 1998) and employment of females in particular. Moreover, while the direct effect of mandatory leaves on fertility rates may be positive, given the potential negative effects of mandated leaves on employment opportunities and wages, females may actually reduce fertility. In fact, the net impact is ambiguous and may differ systematically across female types.

On the empirical side, there are mixed results on the effects of mandated leaves on employment and wages. For instance, Waldfogel (1998a) finds that the length of legislated leaves is associated with increases in the wages of women while Ruhm (1998), using data from European countries, finds that mandated leaves of short duration have negligible effects on wages, and that leaves of long duration are associated with substantial reductions in the wages of women. Similar ambiguous results are found for employment. One limitation of the empirical literature is the difficulty to identify and assess the importance of career interruptions on wages due to human-capital losses. Moreover, these studies abstract from the interaction between labor-market and fertility decisions, the endogeneity of tenure and experience, and from the general-equilibrium effects associated with mandated-leave policies.

In contrast to previous research, our paper quantifies the effects of parental leaves policies on the economy in a general-equilibrium model that is suitable for policy analysis. We 
develop a framework of fertility and labor-market decisions where workers and firms can agree on temporary separations due to childbirth (voluntary leaves). We use this framework to investigate the impact of mandated leaves on fertility, employment, wages, and welfare.

Our framework builds on the Mortensen and Pissarides (1994) labor-matching model in several dimensions. We consider an economy with male and female workers in which females can have children. Females derive utility from having children and from spending time at home with them. Following the evidence in Topel (1991) and others, we allow for humancapital accumulation on the job where part of this capital can be specific to a particular job relationship. We also allow for temporary separations of a worker and a job. Temporary leaves are beneficial in preventing the loss of valuable specific capital, but they imply a cost. In our environment, fertility induces female-labor turnover with potential losses of human capital. The destruction of specific human capital is the prevalent hypothesis in the labor literature as career interruptions are followed by reductions in wages. ${ }^{1}$ Finally, we allow for ex-ante heterogeneity across individuals as differences in education, which we assume constant over time. This assumption allows us to study the distributive effects of mandated leaves across female groups.

Our paper is related to a recent literature of calibrated models on the economics of the family, most notably Aiyagari, et al. (2000), Regalia and Ríos-Rull (1999), and Fernández and Rogerson (2000). Caucutt, et al. (2001) study the timing of births in an environment

\footnotetext{
${ }^{1}$ Phipps, et al. (2001) using a panel of Canadian data show that among a group of employed workers women have a higher job to non-employment turnover (and of longer duration) than males. Also, career interruptions are mostly associated with childbirth for women and lack of job opportunities for males. These job interruptions are associated with reductions in wages. Wood, et al. (1993) present similar evidence by looking at a specific group of highly paid workers in the U.S.
} 
with fertility and marriage decisions. Differently from all these papers, we abstract from marriage issues and focus on labor-market decisions and temporary separations. ${ }^{2}$ Da-Rocha and Fuster (2005) also abstract from marriage issues and develop a quantitative model to study recent observations of fertility rates and female employment ratios in O.E.C.D. countries. In Erosa, et al. (2002), we develop a decision-theoretic framework in order to study the interaction between fertility and labor-supply decisions. Relative to Erosa, et al. (2002), the present paper models temporary separations, the demand side of the labor market, and mandatory-leave policies in order to evaluate the general-equilibrium effects of parental-leave policies.

We consider as our benchmark a situation in which there is no government intervention in the labor market: firms and workers are free to agree on temporary separations. The economy is calibrated to match key features of the labor-market and fertility behavior for the U.S. economy prior to the implementation of parental-leave policies at the federal level in 1993. Our first finding is that when fertility and labor-market decisions interact, labor turnover associated with childbirth causes small losses of human capital. We perform several quantitative policy experiments in order to study the quantitative impact of mandatory parental-leave policies. We introduce mandatory unpaid leaves of short duration and paid leaves with short and long duration. We find that a one-period (12 weeks) unpaid mandatory leave policy has a small impact on aggregate behavior in the economy, in particular employment and wages, consistent with the evidence in Ruhm (1998) for leaves of short duration in European countries, and in Kleirman and Leibowitz (1999) for the U.S. Other more generous

\footnotetext{
${ }^{2}$ There is some evidence that marital status does not change child penalties in wages for women while it generates a large premium in wages for males, Phipps, et al. (2001).
} 
policies have similar aggregate effects. However, we find important changes in fertility and employment behavior across educational groups, as well as substantive (redistributive) effects on steady-state welfare. The introduction of parental-leave policies leads to substantial aggregate (steady-state) welfare losses for newly born people because these policies subsidize inefficient matches and encourage too much leave taking by fertile females. Moreover, we find that the general-equilibrium effect of mandatory-leave policies is to reduce the time that females spend at home with children.

Our analysis proceeds as follows. In the next section, we describe the voluntary leaves environment as our benchmark. We calibrate the benchmark economy to U.S. data before the implementation of the Family and Medical Leave Act in 1993, and evaluate its main properties. Section 3 extends the analysis to un-paid and paid mandatory leaves that resemble the characteristics of current labor markets in the U.S., Canada, and some European countries. In the last section we conclude.

\section{The Benchmark Economy: Voluntary Leaves}

\section{$2.1 \quad$ Economic Environment}

We develop an environment to study temporary and permanent separations between a worker and a job due to fertility, and its impact on human-capital accumulation. To this end, we consider a labor-matching framework along the lines of Mortensen and Pissarides (1994) and incorporate male and female workers, temporary separations of a job-worker match, on-thejob human-capital accumulation, and fertility decisions. We study the impact of fertility and 
labor-market decisions on the human capital accumulated on the job. Below, we describe the environment in detail.

Demographics and Preferences The economy is populated by a large number of adults that face exponential life: in every period there is a constant probability $\rho$ of dying. We assume that there is an equal proportion of males and females. Females can have children when fertile, but face a constant probability $\phi$ of becoming non-fertile every period.

Individuals derive utility from consumption. In addition, females also derive utility from the number of children they have and from time spent with their children. The instantaneous utility function is linear in consumption of goods and time with children, and concave with respect to the number of their children.

The utility value of spending time with children is stochastic. Each period a fertile female draws a value $v$ from an exogenous and time-invariant distribution with cdf $F(v)$. The inter-

temporal discount factor is $\widehat{\beta}$. We denote by $\beta=\widehat{\beta}(1-\rho)$ the effective discount factor, where $(1-\rho)$ is the survival probability.

\section{Technologies}

- Human Capital Individuals are endowed with one unit of productive time each period and do not value leisure. Individuals differ in the amount of productive labor services per unit of time they supply to the market, an object that we call human capital $h$. There are three components to human capital, an education component that is fixed through life and two variable components: general learning by doing (experience) and specific learning by doing (tenure). We assume that the variable components to human 
capital evolve stochastically depending upon labor market attachment and experience. In particular, human capital evolves according to a first-order Markov process. We assume that an individual with job status $j$ and human capital $h$ faces a probability $\pi_{h h^{\prime}}^{j}$ of having a human capital $h^{\prime}$ the next period. We discuss the properties of this process in detail in the calibration section.

- Consumption There is only one good in this economy, and the production technology requires labor input. There is a continuum of entrepreneurs that can create production opportunities without a cost. A production opportunity requires one worker and generates output as a function of the human capital of the worker according to an increasing function $y(h)$.

- Matching Entrepreneurs post vacancies, and workers search for jobs. The search process is costly in the sense that it requires time and resources to form matches. In particular, matches between vacancies and workers are formed according to the following exogenous matching technology: $z(u, o)=k u^{\alpha} o^{1-\alpha}$ with $\alpha \in(0,1)$ and $k>0$ where $u$ is the mass of non-employed workers, $o$ is the mass of vacancies posted, and $z(u, o)$ is the number (mass) of matches formed. The probability that a non-employed worker finds a job is denoted by $p=\frac{z(u, o)}{u}$. The probability that a firm matches a vacancy with a worker is $q=\frac{z(u, o)}{o}$. Matches are subject to an exogenous destruction probability $\lambda$ every period.

Entrepreneurs There is a large number of entrepreneurs with linear preferences over consumption. Entrepreneurs can create production opportunities without a cost and search 
for workers. Posting a vacancy requires $c$ units of the output good every period. If a workervacancy pair is matched, then the following period the production unit can produce, be on leave, or be destroyed. A matched vacancy that is not destroyed faces a fixed cost of $C$ units of output per period, whether the unit is producing or not.

The institutional arrangement that we consider as our benchmark is one with no government intervention in the labor market: workers and entrepreneurs are free to decide production, destruction, and temporary separation. We assume that temporary separations are negotiated every period.

The Problem of a Fertile-Female At the beginning of a period, a fertile female receives a utility value $v$ of spending time with her children in the current period. She can only enjoy this value if she gives birth in the current period, or if she gave birth some time before but has not returned to work since then. We find it convenient to use a state variable $d \in\{0,1\}$ (denoting domestic status) in the following way: $d=1$ (or $d_{1}$ ) if a female can enjoy the current realization of $v$ without having a child in the current period, and $d=0$ (or $d_{0}$ ) if a female cannot enjoy $v$ without having a child in the current period.

Fertile females make a fertility decision and a labor-market decision. We denote the discrete decision to have a newborn child $b \in\{0,1\}$ with the convention that $b=1$ indicates having a newborn child.

We represent the timing of decisions and shocks for a fertile female within a period in the following diagram: 


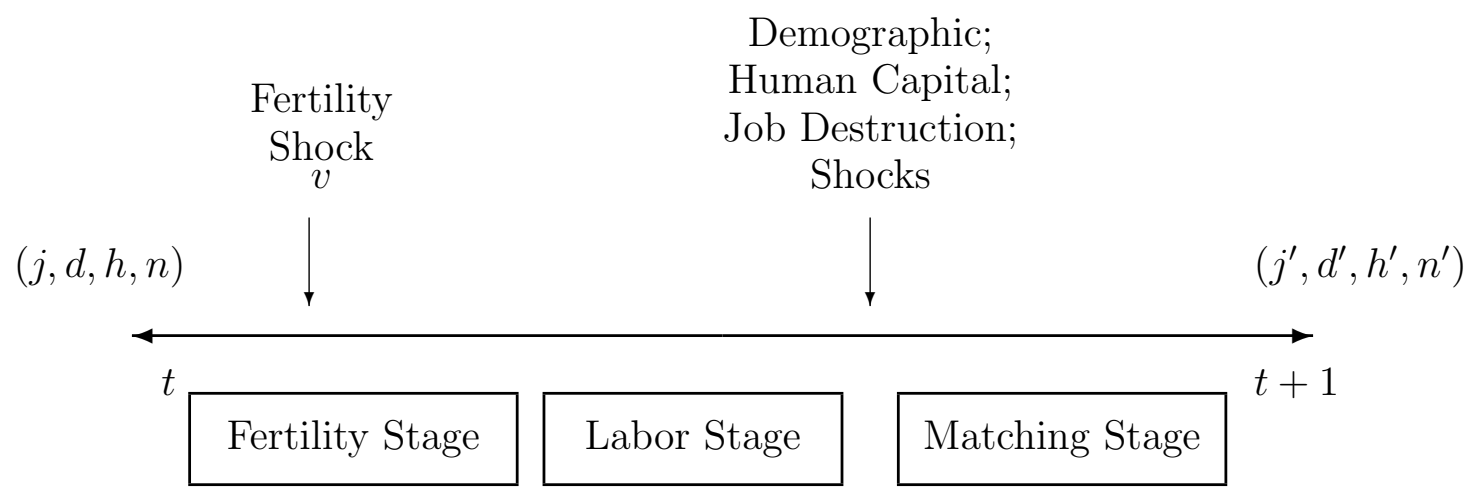

Fertile females start the period with a given 4 -tuple $(j, d, h, n)$ indicating job status (whether they are matched to a job or not), domestic status, human capital, and number of children, respectively. After receiving a draw of $v$, fertile females decide whether to have a newborn child or not. Then, conditional on having a job offer, they decide whether to work, to take a leave, or to destroy the match. Next, the demographic shocks are realized. Individuals die with probability $\rho$ and, conditional on being alive, might become non-fertile with probability $\phi$. When a female becomes non-fertile, her children become adults and enter the labor market by searching for jobs. At the end of the period, human-capital shocks are realized (depending on previous labor-market decisions) and matches are exogenously destroyed with probability $\lambda$. If the individual is not matched, no labor-market decisions are made.

At the beginning of the first stage, fertile females make fertility decisions. We denote by $V$ the value function after fertility decisions are made. The decision problem of fertility can be represented as,

$$
\max \left\{V_{j}^{f}(d, h, n+1, v), V_{j}^{f}(d, h, n, v)\right\}
$$


and $b_{j}(d, h, n, v) \in\{0,1\}$ is the optimal policy rule from this problem. Note that fertility decisions are made after the fertility shock has been realized. We denote by $W$ the value function before the fertility shock is known,

$$
W_{j}^{f}(d, h, n)=\int_{v} \max \left\{V_{j}^{f}\left(d_{1}, h, n+1, v\right), V_{j}^{f}(d, h, n, v)\right\} d F(v) .
$$

A fertile female that has an employment offer or currently matched $(j=o)$ decides whether to accept $(A)$, to reject $(R)$, or to be on leave $(L)$. We represent the decision problem as follows,

$$
V_{o}^{f}(d, h, n, v)=\max \left\{A^{f}(d, h, n, v), R^{f}(d, h, n, v), L^{f}(d, h, n, v)\right\}
$$

The value of accepting a job offer $A$ is given by,

$$
\begin{aligned}
A^{f}(d, h, n, v)= & w^{f}(d, h, n, v)+\gamma_{n} \log (1+n) \\
& +\beta(1-\phi)(1-\lambda) \sum_{h^{\prime}} W_{o}^{f}\left(d_{0}, h^{\prime}, n\right) \pi_{h h^{\prime}}^{a} \\
& +\beta(1-\phi) \lambda \sum_{h^{\prime}} W_{n o}^{f}\left(d_{0}, h^{\prime}, n\right) \pi_{h h^{\prime}}^{r} \\
& +\beta \phi\left[(1-\lambda) \sum_{h^{\prime}} W_{o}^{n}\left(h^{\prime}, n\right) \pi_{h h^{\prime}}^{a}+\lambda \sum_{h^{\prime}} W_{n o}^{n}\left(h^{\prime}, n\right) \pi_{h h^{\prime}}^{r}\right] .
\end{aligned}
$$

The first two terms represent the current period utility which is given by the wage rate and the utility of children. Conditional on her being alive next period, the expected value for the female next period depends on whether she remains fertile, whether the job is not exogenously destroyed, and on the evolution of human capital, which in turn depends on 
labor-market decisions. This expected value is represented in the next three terms. Note that conditional on accepting a job in the current period, domestic status in the following period is $d_{0}$.

The value of rejecting a job offer $R$ is given by,

$$
\begin{aligned}
R^{f}(d, h, n, v)= & v d+\gamma_{n} \log (1+n) \\
& +\beta(1-\phi) \sum_{h^{\prime}} p W_{o}^{f}\left(d, h^{\prime}, n\right) \pi_{h h^{\prime}}^{r} \\
& +\beta(1-\phi)(1-p) \sum_{h^{\prime}} W_{n o}^{f}\left(d, h^{\prime}, n\right) \pi_{h h^{\prime}}^{r} \\
& +\beta \phi \sum_{h^{\prime}}\left[p W_{o}^{n}\left(h^{\prime}, n\right)+(1-p) W_{n o}^{n}\left(h^{\prime}, n\right)\right] \pi_{h h^{\prime}}^{r}
\end{aligned}
$$

If a female stays at home, she receives the utility $v d$, but her labor income is zero. Conditional on being alive, there is a probability $p$ of receiving a job offer next period, and human capital evolves according to $\pi^{r}$.

The value of being on leave $L$ is given by,

$$
\begin{aligned}
L^{f}(d, h, n, v)= & w_{f}^{l}(d, h, n, v)+v d+\gamma_{n} \log (1+n) \\
& +\beta(1-\phi)(1-\lambda) \sum_{h^{\prime}} W_{o}^{f}\left(d, h^{\prime}, n\right) \pi_{h h^{\prime}}^{l} \\
& +\beta(1-\phi) \lambda \sum_{h^{\prime}} W_{n o}^{f}\left(d, h^{\prime}, n\right) \pi_{h h^{\prime}}^{r} \\
& +\beta \phi\left[(1-\lambda) \sum_{h^{\prime}} W_{o}^{n}\left(h^{\prime}, n\right) \pi_{h h^{\prime}}^{l}+\lambda \sum_{h^{\prime}} W_{n o}^{n}\left(h^{\prime}, n\right) \pi_{h h^{\prime}}^{r}\right] .
\end{aligned}
$$

The first term represents the wage when the female is on leave. This wage is negotiated through bargaining and can be negative since the firm and the worker may share the cost 
of maintaining the match to preserve valuable specific capital. When on leave, a fertile female receives utility from staying at home with her children $v d$ and utility from having children. Conditional on the match not being exogenously destroyed, and contrary to when a fertile female is not employed, she receives in the following period an employment offer with probability 1, and human capital evolves according to $\pi_{h h^{\prime}}^{l}$ instead of $\pi_{h h^{\prime}}^{r}$.

An unmatched fertile female $(j=n o)$ does not make any decisions in the second stage. Her value coincides with that of a fertile female who rejects a job offer,

$$
V_{n o}^{f}(d, h, n, v)=R^{f}(d, h, n, v) .
$$

The Problem of a Non-Fertile Female and a Male We assume that when a fertile female becomes non-fertile, her children leave home and become adults, and that she no longer derives utility from spending time at home with children. Therefore, at the beginning of the period, the state of a non-fertile female includes job status, human capital, and number of children. Non-fertile females only make labor market decisions.

A non-fertile female with a job-offer considers whether to accept or reject the offer. It is straightforward to show that leaves are never an optimal choice for non-fertile females in this environment. Therefore, the value of an offer for a non-fertile female is the maximum of two options,

$$
V_{o}^{n f}(h, n)=\max \left\{A^{n f}(h, n), R^{n f}(h, n)\right\}
$$

where the value of accepting and rejecting are simpler versions of the values for fertile females. A non-fertile female without a job offer does not make any decision and, therefore, the value 
of not having a job offer $(n o)$ is the same as the value of rejecting a job offer,

$$
V_{n o}^{n f}(h, n)=R^{n f}(h, n)
$$

At the beginning of the period, a male has job status and human capital as state variables. Therefore, the male problem in our environment is equivalent to the one of a non-fertile female with zero children.

The Value of a Job for the Entrepreneur A matched production unit must pay a fixed cost $C$ per period whether active or not. A production unit generates output as an increasing function of the human capital of the worker $y(h)$ net of the fixed $\operatorname{cost} C$. The value of a job is assumed to be non-negative since matches can be broken at no cost.

The value of a job with a fertile female is the maximum between the value of producing, being on leave, and breaking the match. Formally,

$$
J^{f}(d, h, n, v)=\max \left\{J_{a}^{f}(d, h, n, v), J_{l}^{f}(d, h, n, v), 0\right\}
$$

where the value of an active job is given by

$$
\begin{aligned}
J_{a}^{f}(d, h, n, v)= & y(h)-w^{f}(d, h, n, v) \\
& +\beta(1-\phi)(1-\lambda) \sum_{h^{\prime}} \int_{v^{\prime}}\left[b_{o}\left(d_{0}, h^{\prime}, n, v^{\prime}\right) J^{f}\left(d_{1}, h^{\prime}, n+1, v^{\prime}\right)\right. \\
& \left.+\left(1-b_{o}\left(d_{0}, h^{\prime}, n, v^{\prime}\right)\right) J^{f}\left(d_{0}, h^{\prime}, n, v^{\prime}\right)\right] d F\left(v^{\prime}\right) \pi_{h h^{\prime}}^{a} \\
& +\beta \phi(1-\lambda) \sum_{h^{\prime}} J^{n f}\left(h^{\prime}, n\right) \pi_{h h^{\prime}}^{l}
\end{aligned}
$$


and the value of a job temporarily on leave is given by,

$$
\begin{aligned}
J_{l}^{f}(d, h, n, v)= & -C-w_{l}^{f}(d, h, n, v) \\
& +\beta(1-\phi)(1-\lambda) \sum_{h^{\prime}} \int_{v^{\prime}}\left[b_{o}\left(d, h^{\prime}, n, v^{\prime}\right) J^{f}\left(d_{1}, h^{\prime}, n+1, v^{\prime}\right)\right. \\
& \left.+\left(1-b_{o}\left(d, h^{\prime}, n, v^{\prime}\right)\right) J^{f}\left(d, h^{\prime}, n, v^{\prime}\right)\right] d F\left(v^{\prime}\right) \pi_{h h^{\prime}}^{l} \\
& +\beta \phi(1-\lambda) \sum_{h^{\prime}} J^{n f}\left(h^{\prime}, n\right) \pi_{h h^{\prime}}^{l} .
\end{aligned}
$$

The value of a job with a non-fertile female and male are simpler versions of the value functions described above.

Wage Determination The decisions of firms and workers regarding whether to accept, to be on leave, or to break the match must maximize the total surplus of the match

$$
\max \left\{A^{i}(s)-R^{i}(s)+J_{a}^{i}(s) ; L^{i}(s)-R^{i}(s)+J_{l}^{i}(s) ; 0\right\}
$$

where $i \in\{m, f, n f\}$ and $s$ is the state of either a male, fertile female or non-fertile female, depending on whose problem we are considering. ${ }^{3}$

If the firm and the worker decide not to break the match, then the wage is determined by a generalized Nash bargaining process. In particular, the wage rate is such that the value for the worker is the value of the outside alternative plus a proportion $\varepsilon$ of the surplus, and similarly for the entrepreneur with a share of $1-\varepsilon$ of the surplus. The wage rates of an

\footnotetext{
${ }^{3}$ The state of the household $s$ at the beginning of the period is given by $(d, n, h, v)$ in the case of a fertile female, $(h, n)$ in the case of a non-fertile female, and $(h)$ in the case of a male.
} 
individual accepting and on leave are given by,

$$
\begin{aligned}
A^{i}(s)-R^{i}(s) & =\frac{\varepsilon}{1-\varepsilon}\left[J_{a}^{i}(s)-0\right] \\
L^{i}(s)-R^{i}(s) & =\frac{\varepsilon}{1-\varepsilon}\left[J_{l}^{i}(s)-0\right]
\end{aligned}
$$

Note that the outside opportunity for the individual with an offer is the value of rejecting the job. Similarly, the outside opportunity for the firm is given by the value of posting a new vacancy, which is zero in equilibrium.

Distributions of Households The population is composed of males, fertile females, nonfertile females, and children. We denote the mass of each of these demographic groups by $m, f, n f$, and $c h$, respectively, and the fraction of fertile females that give birth by $B_{t}$. The laws of motion of the population of each of the demographic groups are as follows:

$$
\begin{aligned}
c h_{t+1} & =(1-\phi)\left(c h_{t}+B_{t} f_{t}\right), \\
m_{t+1} & =(1-\rho) m_{t}+\frac{1}{2} \phi\left(c h_{t}+B_{t} f_{t}\right), \\
f_{t+1} & =(1-\rho)(1-\phi) f_{t}+\frac{1}{2} \phi\left(c h_{t}+B_{t} f_{t}\right), \\
n f_{t+1} & =(1-\rho) n f_{t}+(1-\rho) \phi f_{t} .
\end{aligned}
$$

The mass of children at date $t+1$ is given by the fraction of children $\left(c h_{t}+B_{t} f_{t}\right)$ that do not become adults at date $t$ (because the mother does not become non-fertile). We assume that half of all newborn children are females in order to keep the gender distribution of the adult population constant over time. 
We denote by $X_{f}$ the distribution of states $(j, d, h, n)$ across fertile females at the beginning of the period. $X_{n f}$ denotes the distribution of states $(j, h, n)$ across non-fertile females and $X_{m}$ denotes the distribution of states $(j, h)$ across males at the beginning of the period. Therefore, we can define the fraction of fertile females that give birth as

$$
B_{t}=\int_{j, d, h, n, v} b_{j}(d, h, n, v) X_{f}(j, d, h, n) d F(v)
$$

The Value of a Vacancy We denote by $Z_{f}$ the distribution of states $(d, h, n)$ across fertile females without a job offer after the shock on their human-capital accumulation is realized. We define $Z_{n f}$ as the distribution of states $(h, n)$ across non-fertile females without a job offer, and $Z_{m}$ the distribution of states $(h)$ across males without a job offer after the human-capital accumulation shock is realized. When a firm is matched with a worker, the firm draws a type of worker (an individual's state) from the distribution that corresponds to the worker's demographic group $(f, n f$, or $m)$.

Population Growth Rate The total population next period equals the population in the current period plus the newborn children minus the number of deaths, that is,

$$
P_{t+1}=P_{t}+f_{t} B_{t}-\rho P_{t}
$$


where $P_{t}$ denotes the population at period $t, P_{t}=m_{t}+n f_{t}+f_{t}+c h_{t}$. In a steady state, the rate of growth of population, $g$, is constant; that is, $P_{t+1}=(1+g) P_{t}$ and, thus,

$$
g P_{t}=f_{t} B_{t}-\rho P_{t}
$$

\subsection{Calibration of Benchmark Economy}

The Family and Medical Leave Act (F.M.L.A.) instituting three months of unpaid maternity leave was approved by the U.S. Congress in 1993. We thus calibrate our benchmark economy (an economy with voluntary leaves) to U.S. data prior to $1993 .{ }^{4}$ Whenever possible, we use data for 1988 that are less likely to be affected by changes in behavior due to the expectation of the passage of the F.M.L.A. ${ }^{5}$ The objective of our calibration procedure is to make the equilibrium of the model with voluntary leaves consistent with observations relevant for the purpose of our research question: employment levels of males and females, humancapital accumulation, wage differences, and fertility rates. As it stands, however, the model cannot reproduce observations along all of these dimensions. For this reason, we introduce three additional features into the model economy: First, in order to generate a reasonable distribution of number of children across females and a reasonable age of motherhood, we assume that females cannot have children in every period of their fertile lifetime. Second, in order to generate plausible fertility rates across females of different education groups,

\footnotetext{
${ }^{4}$ Waldfogel (1998a) documents that about 50\% of females had some maternity leave coverage before 1993. We think, however, that most of these leaves can be understood as voluntary contracts between firms and workers.

${ }^{5}$ The Pregnancy Discrimination Act was approved in 1978 and our benchmark model does not allow for discrimination: vacancies are posted in a single market with random matching.
} 
we assume that children are costly both in terms of time and goods. Third, in order to generate plausible gender and family wage gaps, we introduce exogenous gender and family productivity gaps. ${ }^{6}$ Below, we explain our calibration procedure and the role of the three model features just described.

Time and Demographic Parameters The length of the model period is inversely related to the computational cost of our model economy. Since our calibration exercise involves finding 10 parameter values to match 10 data targets, choosing the length of the period is a non-trivial issue. We choose a model period of one quarter because it is the longest period that allows us to study the mandated leave policies instituted by the F.M.L.A. in the U.S. (mandated leaves last 12 weeks, i.e., a quarter). Mandated leaves in European countries are typically longer than a quarter and may last for a year (4 model periods). Furthermore, by choosing a model period of a quarter and assuming that the value of staying at home is drawn each period from an iid distribution over time, we obtain some "persistence" in the value of staying at home at a low computational cost. The time preference parameter $\beta$ is selected to match an annual interest rate of $4 \%$. The probability of dying in a period $\rho$ is selected to reproduce a working-life expectancy of 45 years. Similarly, the probability of becoming non-fertile is selected to reproduce an expected fertile life of 20 years. $^{7}$

\footnotetext{
${ }^{6}$ The gender gap usually refers to the average wage (earnings or productivity) ratio between females and males while the family gap refers to the average wage (earnings or productivity) ratio between mothers and non-mothers.

${ }^{7}$ For non-fertile, the probability of dying is adjusted to generate an expected life after becoming non-fertile of 25 years.
} 
Human Capital: Education, Experience, and Tenure In our model economy, human capital (labor productivity) depends on three factors: $(a)$ formal education, which is fixed through the individual's life; $(b)$ general experience, which accumulates with time working; and $(c)$ specific tenure, which accumulates with time working within a job. We assume three educational types interpreted as high school or less, college dropouts and associate degrees, and complete college or more. The distribution of the adult population across these types is calibrated using U.S. Census data from Bachu and O'Connell (2000). The output of the first educational type, with no experience and no tenure, is normalized to 1 . The output of the other two educational types, with no experience and no tenure, is fixed so that the average wage of males in these two educational categories relative to the least educated males is consistent with wage differentials across these groups in the data. ${ }^{8}$

We use estimates from Topel (1991) in order to select values for general (experience) and specific (tenure) human capital. We assume that human capital increases with experience and tenure at the same rate for all educational types and across genders. For ease of computation, experience and tenure are restricted to take values in the set $\{0,1, \ldots, 10\}$ expressed in years (i.e., only multiples of a year are allowed) and evolve stochastically over time as follows: ${ }^{9}$

1. Experience and tenure jointly increase by a year with probability $1 / 4$ if an individual works during the current period (recall that the model period is a quarter).

\footnotetext{
${ }^{8}$ Relative output does not correspond entirely with relative wage because of tenure and experience, but it represents a close approximation.

${ }^{9}$ The cumulative increases in labor productivity are given by 1.00, 1.0697, 1.1356, 1.1973, 1.2544, 1.3070, $1.3551,1.3992,1.4396,1.4773,1.5130,1.5478,1.5830,1.6198,1.6597,1.7045,1.7561,1.8166,1.8887,1.9756$, 2.0809 for experience between 0 to 10 years and by 1.00, 1.0514, 1.0964, 1.1354, 1.1685, 1.1963, 1.2194, 1.2385, $1.2543,1.2675,1.2788$ for tenure between 0 to 10 years. These values are such that an average individual in the model economy has an experience profile and tenure profile of wages similar to those estimated by Topel (1991).
} 
2. Experience remains constant during work interruptions (leaves or break-ups), as suggested by evidence in Topel (1991), Albrecht, et al. (1999), Phipps, et al. (2001), and Wood, et al. (1993).

3. Tenure remains constant during temporary separations, but it is set to 0 with permanent separations. For evidence on the behavior of wages during temporary and permanent separations see Phipps, et al. (2001), Albrecht, et al. (1999), and Wood, et al. (1993).

Exogenous Productivity Gaps The model features fertility and labor market decisions to generate differences in human-capital accumulation on the job across gender and family (motherhood) status. The model abstracts from other relevant features that might be important in accounting for gender and family wage differences (such as, the possibility of less effort put into accumulating human capital by mothers when working, discrimination in hiring, promotion, and the allocation of firm-provided training). Therefore, we assume that labor productivity of a female is $\omega_{\text {gender }}$ points lower than the labor productivity of a male with the same experience and tenure. In addition, we assume that the labor productivity of mothers is reduced by $\omega_{\text {family }}$ points per child. As a result, the labor productivity $(y+C)$ of a female with $n$ children, education $e d$, general human capital ge, and specific capital $s p$ is equal to

$$
\left(1-\omega_{\text {gender }}\right)\left(1-\omega_{\text {family }} n\right) h_{e d}(e d) h_{g e}(g e) h_{s p}(s p)
$$

where $h_{e d}(e d), h_{g e}(g e), h_{s p}(s p)$ represent the cumulative increase in productivity due to education level ed, experience $g e$, and tenure $s p$. (Notice that $\left.h_{e d}(1)=h_{g e}(1)=h_{s p}(1)=1\right)$. 
The parameters $\left(\omega_{\text {gender }}, \omega_{\text {family }}\right)$ are calibrated to match, together with the endogenous factors in the model, the gender and family wage gaps in the U.S. economy. Blau and Kahn (2000) report a gender wage ratio of 0.805 when adjusting for age, education, and experience differences between individuals in the sample (the un-adjusted wage ratio is 0.724 ). Waldfogel (1998) reports that after controlling for age, education, experience, year, and individual fixed effects, on average, a child reduces women's wages by 4.6 percent. We emphasize that in our model these gaps can have important consequences for fertility and labor-market behavior, so it is crucial that the model is consistent with relative wage observations.

Fertility Opportunities We assume that females face a stochastic shock, fertility opportunity, determining whether they can consider having a child or not. A model without fertility opportunities would imply that a large number of non-employed females have children, most of them one immediately after the other, which would be inconsistent with the biological time required between births. More importantly, fertility opportunities allow us to match the average age of mothers when they give birth for the first time and the distribution of number of children across women. These observations are relevant for two reasons: First, the age at which females give birth in our model is likely to be related to tenure on the job and, thus, with the specific human capital that the female would lose if she quits her job. Second, the number of children in our model is a crucial determinant of women's labor-market behavior.

We introduce fertility opportunities, as a vector $\sigma$, where $\sigma(i)$ represents the probability that a fertile female can have the $i$-th child. Then, the value function $W$ in equation (1) 
takes the following form,

$$
W_{j}^{f}(d, h, n)=\int_{v}\left\{\begin{array}{c}
\sigma(n+1) \max \left\{V_{j}^{f}\left(d_{1}, h, n+1, v\right), V_{j}^{f}(d, h, n, v)\right\} \\
+(1-\sigma(n+1)) V_{j}^{f}(d, h, n, v)
\end{array}\right\} d F(v) .
$$

We restrict the maximum number of children that a female can have to six; however, we do not think that this is a severe restriction since the fraction of women with more than six children in the data is less than 0.3 percent. We select the values of the vector $\sigma$ so that the first three components are equal to 0.05 and the last three components are equal to 0.025 . Below, we argue that this procedure allows our benchmark economy to produce an average age of first birth and a distribution of children across women that are roughly consistent with the data.

Cost of Children We assume that each child reduces the female labor supply (e.g., hours worked) in $\tau$ units, and costs $\psi$ units of goods per period. These costs are only incurred while the mother is fertile. In particular, we assume that when a female becomes non-fertile her children become adults and, thus, they are no longer costly. There is substantial evidence that children are costly both in terms of goods and of time supplied to the labor market. More importantly, modeling the cost of children allows our calibrated economy to deliver fertility rates by education that are consistent with the data. This turns out to be important for generating an appropriate amount of female labor turnover since fertility decisions are closely related to labor turnover in our model. We calibrate the cost of children in terms of goods, $\psi$, so that the equilibrium of the benchmark model reproduces the fertility rate for 
women with low education. According to U.S. Census data reported by Bachu and O'Connell (2000), women with an educational attainment of a high school degree or less have a fertility rate of 2.46 children, and we use this statistic as a calibration target. We set the time cost per child $\tau$ to 10 percent which is close to estimates made by Angrist and Evans (1998), and others. These values of $\psi$ and $\tau$ generate an aggregate cost of children to a GDP ratio of 16 percent in our model. The value in the U.S. economy of such statistic is estimated to be 10 percent by Haveman and Wolfe (1995). However, this number cannot be directly compared with the one generated by our model because our economy does not have capital. Using a labor income share of 0.36 , we estimate the cost of children to labor-income ratio in the data to be around 16 percent, so that our benchmark economy exactly matches this statistic.

Matching Technology Following Blanchard and Diamond (1989) we assume a constant returns-to-scale matching technology, $z(u, o)=k u^{\alpha} o^{1-\alpha}$. These authors estimate $\alpha=0.4$ using monthly U.S. data. With the Cobb-Douglas specification, the probabilities that a vacancy and a worker find a match are given by $q=k\left(\frac{u}{o}\right)^{\alpha}$ and $p=k\left(\frac{v}{o}\right)^{1-\alpha}$, respectively. According to van Ours and Ridders (1992), the average duration of a vacancy in the U.S. economy is 45 days. Following Andolfatto (1998), we use this statistic to compute the probability that a vacancy is matched in a quarter as $q=1-\left(1-\frac{1}{45}\right)^{90}=0.8677$. The Economic Report of the President states that the average duration of non-employment is 12 weeks, which implies a probability of being matched in a day of $1 / 84$, and therefore $p=1-\left(1-\frac{1}{84}\right)^{90}=0.6597$. Using the targets for $p$ and $q$, the equations defining these two probabilities, and the value $\alpha=0.4$, we obtain $\frac{u}{o}=1.3153$ and $k=0.7776$. We then 
calibrate the cost of a vacancy $c$ so that in equilibrium $\frac{u}{o}=1.3153$. Once this target is matched, and as our discussion of the calibration of $k$ shows, the targets for $p$ and $q$ are automatically matched.

Bargaining There is little empirical evidence that can be used to estimate the parameter describing the bargaining power of workers in the Nash bargaining equation, $\varepsilon$. We find that this parameter plays a key role in determining the aggregate cost of vacancies over GDP in our environment. When $\varepsilon$ is low, the value of a match for the firm is high as the firm obtains a large portion of output. A large number of vacancies must be posted in equilibrium to generate zero profits, and the total cost of vacancies over GDP is high. When $\varepsilon$ is high, the value of a match is low, and less vacancies are required to make the value of a vacancy zero in equilibrium. Therefore, the total cost of vacancies over GDP is low. We select $\varepsilon=0.9$ which generates a cost of vacancies over GDP close to 2 percent. ${ }^{10}$

Calibration of Other Parameters Given a set of parameter values, finding an equilibrium in our model economy involves finding a non-employment to vacancy ratio so that the value of a vacancy is equal to zero. We have yet to specify the values of 10 parameters: the exogenous job destruction $\lambda$, the preference parameter for the number of children $\gamma_{n}$, the cost of children (goods) $\psi$, the mean and the standard deviation of fertility-home shock $\left(\mu_{v}, \sigma_{v}\right)$, the cost of posting a vacancy $c$, the cost of keeping a match $C$, the parame-

\footnotetext{
${ }^{10}$ Our model abstracts from the value of leisure and home production. A model with these features would increase the outside alternative for workers, diminishing the surplus to be shared between the worker and the firm, and the value of vacancies. This would reduce the number of vacancies posted in equilibrium and therefore the total cost of vacancies over GDP. Hence, a lower target for the cost of vacancies over GDP can be achieved with the same value of $\varepsilon$ if these features were considered.
} 
ter $k$ in the matching technology, and the exogenous gender and family productivity gaps $\left(\omega_{\text {gender }}, \omega_{\text {family }}\right)$. The values of these parameters are chosen so that the equilibrium of the voluntary-leaves model reproduces the targets for the following 10 statistics: employment-topopulation ratio of males, aggregate fertility rate, fertility rate of females with low education level, employment-to-population ratio of mothers with infants (children less than one year old), probability of matching a vacancy, fraction of mothers of a three-month-old child who are on leave, employment-to-population ratio of fertile females, gender wage gap, family wage gap, and probability of finding a job. We solve for an equilibrium and the calibration at the same time. As a result, our procedure involves solving numerically a system of 11 variables to match 11 targets (10 calibration targets and the equilibrium zero-profit condition for vacancies).

Discussion of Data Targets A short remark on the choice of some of the data targets is worth making. First, because there is an important time trend in the employment of women, the aggregate employment-to-population ratios of older women tend to be lower than those of women of recent cohorts. Because our model abstracts from this time trend, we choose a target of employment of younger women which is less subject to a time trend. Using U.S. Census data, Bachu and O'Connell (2000) report an employment-to-population ratio of women aged 25 to 44 of 0.66 . We choose this number to be our target for the employmentto-population ratio of fertile females. Second, our calibration also targets the employmentto-population ratio of mothers with infants, and the fraction of mothers with 3-month-old children who are on leave. By targeting the labor market behavior of women after childbirth, 
our calibration emphasizes the importance of matching female labor turnover associated with childbirth. The target statistics are obtained from Kleirman and Leibowitz (1994) who use data from the Current Population Survey and supplements for recent mothers. These authors report an employment-to-population ratio of mothers with infants of 45 percent and a fraction of 8.2 percent of mothers with 3-month-old children who are on leave.

Table 1 summarizes the parameter values that are selected without solving the model, and Table 2 reports the values of the parameters calibrated by solving the model and the target statistics.

Table 1: Parameters Calibrated without Solving the Model

\begin{tabular}{lc}
\hline Parameter & Value \\
\hline$\beta$ - time preference & 0.99 \\
$\rho$ - probability of dying & 0.0056 \\
$\phi$ - probability of becoming non-fertile & 0.007 \\
$\tau$ - time cost of children & 0.10 \\
$\varepsilon$ - bargaining power of workers & 0.90 \\
$\alpha$ - matching technology & 0.40 \\
Distribution of individuals across education: & \\
Edu1 (HS or less) & 0.4 \\
Edu2 (Dropout) & 0.3 \\
Edu3 (College) & 0.3 \\
Relative output by education: & \\
Edu1 (HS or less) & 1.0 \\
Edu2 (Dropout) & 1.3 \\
Edu3 (College) & 2.2 \\
Fertility opportunities: & \\
$\sigma(1)=\sigma(2)=\sigma(3)$ & 0.05 \\
$\sigma(4)=\sigma(5)=\sigma(6)$ & 0.025 \\
\hline
\end{tabular}


Table 2: Parameters Calibrated by Solving the Model and Data Targets

\begin{tabular}{cc|lc}
\hline Parameter & Value & Target & Value \\
\hline$\lambda$ & 0.13 & Employment-to-population ratio of males & 0.86 \\
$\gamma_{n}$ & 1.26 & Fertility rate & 2.1 \\
$c$ & 0.16 & Probability of matching a vacancy & 0.87 \\
$C$ & 0.20 & Mothers of 3-month-old child on leave & 0.08 \\
$\mu_{v}$ & 0.66 & Employment-to-population ratio of fertile females & 0.66 \\
$\sigma_{v}$ & 1.92 & Employment-to-population ratio of mothers with infants & 0.45 \\
$\psi$ & 0.24 & Fertility rate of females with low education & 2.46 \\
$\omega_{\text {gender }}$ & 0.12 & Gender wage gap & 0.20 \\
$\omega_{\text {family }}$ & 0.046 & Family wage gap & 0.10 \\
$k$ & 0.77 & Probability of finding a job & 0.66 \\
\hline
\end{tabular}

\subsection{Properties of the Benchmark Economy}

In this section, we show that the calibrated economy is consistent with U.S. data on fertility rates, employment-to-population ratios, and wage gaps. We think that, as a first step, our paper is successful in building a quantitative theory of labor-market and fertility decisions in the U.S. economy. Below, we present statistics of our benchmark economy in order to help the reader understand how it behaves. A major finding of this section is that specific (tenure) human capital plays a minor role in accounting for the gender and family wage gaps.

Calibration Results Table 3 compares the results of our benchmark economy with U.S. data along the targets specified in the calibration section. The model matches very closely the targets for male and female employment, leaves, fertility, and wage gaps. In particular, the model matches almost exactly the targets for employment-to-population ratios of fertile females and mothers with infants together with the target for the fraction of women of 3-month-old children who are on leave. Fertility has an important impact on female employ- 
Table 3: Calibration Results: Targets

\begin{tabular}{lcc}
\hline Target & Data & Model \\
\hline Employment-to-population ratio of males & 0.86 & 0.85 \\
Fertility rate & 2.1 & 2.1 \\
Probability of matching a vacancy $(q)$ & 0.87 & 0.81 \\
Mothers with 3-month-old children on leave & 0.08 & 0.08 \\
Employment-to-population ratio of fertile females & 0.66 & 0.66 \\
Employment-to-population ratio mothers with infants & 0.45 & 0.44 \\
Fertility rate of females with low education & 2.46 & 2.43 \\
Gender wage gap & 0.20 & 0.20 \\
Family wage gap & 0.10 & 0.10 \\
Probability of finding a job $(p)$ & 0.66 & 0.70 \\
\hline
\end{tabular}

ment, both in our model and in the data. While 66 percent of fertile females are employed, the employment-to-population ratio of mothers with infants is only 45 percent. These observations suggest that the model economy is generating plausible amounts of labor-market turnover due to fertility decisions.

Employment and Fertility by Education Table 4 shows statistics on fertility and female employment by education level. Notice that, both in the U.S. data and in the benchmark economy, employment levels increase and fertility rates decrease with the level of education. The model economy generates differences in female employment across education groups that are larger than those observed in the U.S. economy. We think, nevertheless, that employment across educational categories in the model economy is not far off from the data.

Fertility and Labor Turnover by Education The difference between employment of fertile females, and employment of mothers with infants provides a measure of the impact 
Table 4: Employment and Fertility

\begin{tabular}{lccc}
\hline & Edu1 & Edu2 & Edu3 \\
\hline Fertility Rate: & & & \\
$\quad$ Model & 2.43 & 2.24 & 1.54 \\
Data & 2.5 & 2.0 & 1.7 \\
\hline Employment-to-Population: & & & \\
$\quad$ Model & 0.49 & 0.72 & 0.84 \\
Data & 0.59 & 0.69 & 0.74 \\
\hline
\end{tabular}

of fertility decisions on employment. Table 5 shows that fertility has a negative impact on the employment of females regardless of the educational category. Notice that the reduction in employment is large for females in the first two educational groups: the employmentto-population ratio of mothers with infants is 23 and 24 percentage points lower than the employment ratio of fertile females in the first two educational categories.

Table 5: Employment of Fertile Females and Mothers with Infants

\begin{tabular}{lccc}
\hline & Edu1 & Edu2 & Edu3 \\
\hline Employment-to-Population: & & & \\
Fertile Females & 0.49 & 0.72 & 0.84 \\
Mothers with Infants & 0.26 & 0.48 & 0.77 \\
\hline
\end{tabular}

Another way to evaluate the impact of fertility on labor-market decisions is to consider the decisions of females who have just given birth and are matched with a job: among these females, 38 percent work, 51 percent permanently separate, and 11 percent temporarily separate from the job for at least one period. Table 6 shows that, among females in the first educational category that give birth and are matched with a job, 74 percent decide to break the job match (reject), while for highly educated females, 73 percent return to 
work immediately after giving birth. ${ }^{11}$ Note that, in all educational categories, there is a non-negligible fraction of females taking leaves of at least a period (three or more months). This occurs even though leaves are costly for them. In fact, females on leave make a side payment to their employer (receive a negative wage) so that the match is not broken while they enjoy staying with their child at home. The average wage among females on leave in the first, second, and third educational categories, normalized by average female earnings in each group, are $-0.26,-0.21$, and -0.13 , respectively.

Table 6: Labor-Market Decisions of Females Giving Birth (fraction)

\begin{tabular}{lcccc}
\hline & Aggregate & Edu1 & Edu2 & Edu3 \\
\hline Accept & 0.38 & 0.22 & 0.34 & 0.73 \\
Reject & 0.51 & 0.74 & 0.51 & 0.11 \\
Leave & 0.11 & 0.05 & 0.15 & 0.17 \\
\hline
\end{tabular}

The previous results document the close interaction between fertility and labor-market decisions and illustrate the importance of jointly modeling these decisions. It is thus important that our benchmark economy generates fertility rates, at the aggregate level and across educational categories, that are consistent with the data. We think, however, that we should be cautious in interpreting the fertility statistics in our model. The reason is that there are many possible distributions of number of children across females that deliver the same fertility rate, but these distributions can have different implications for female employment. In other words, the number of children a female has plays a crucial role in determining labormarket decisions. Consequently, it is important that our benchmark economy delivers not

\footnotetext{
${ }^{11}$ We interpret this observation as 73 percent of females with high education return to work, with the same employer, within the three-month period after giving birth.
} 
only plausible fertility rates but also a plausible distribution of number of children across females.

Table 7: Distribution of Number of Children across Women

\begin{tabular}{lcc}
\hline & Data $^{*}$ & Model $^{* *}$ \\
\hline No child & 19.0 & 20.7 \\
One child & 17.3 & 16.4 \\
Two children & 35.8 & 25.3 \\
Three children & 18.2 & 17.5 \\
4 children or more & 9.6 & 20.0 \\
\hline
\end{tabular}

${ }^{*}$ Women $40-44$ years of age, ${ }^{* *}$ Non-fertile Females

Table 7 compares the distribution of number of children across women between 40 and 44 years of age in the U.S. data with the distribution of children across non-fertile females in our benchmark economy (e.g., women that have completed their fertility stage). The first column in the table contains data taken from the June Supplement to the 1998 CPS and the second column contains statistics from our calibrated economy. Again, we warn the reader to be cautious when comparing the model implications with the data. The reason is that while our model was calibrated to an aggregate fertility rate of 2.1 , the data in the first column implies an average of 1.8 children per woman. ${ }^{12}$ Therefore, we could not ask the model to reproduce the fertility rate together with the distribution of children in the first column. However, this comparison shows that the model generates a reasonable distribution of number of children across females. The largest differences are that the model understates the number of women with two children and overstates the number of women with four or

\footnotetext{
${ }^{12}$ Note that fertility rates in the U.S. are not constant over time. Thus, it should not be surprising that the mean of the distribution of children among 40-44-year-old women does not coincide with our target for the fertility rate in the U.S.
} 
more children. In Table 8 we present the average age of motherhood for a different number of births. These statistics were computed by simulating the model in order to follow a cohort of females and compute an age-at-birth number. We assume, in doing this computation, that females with education level of 1,2, and 3, start their working life at ages 16, 18, and 20. Exogenous fertility opportunities closely determine the age of motherhood for the first and second child, while the age of motherhood for the third child is more influenced by individual characteristics such as human capital and labor-market status.

Table 8: Average Age of Motherhood

\begin{tabular}{cccc}
\hline & Edu1 & Edu2 & Edu3 \\
\hline Child number: & & & \\
First & 19.8 & 21.8 & 23.8 \\
Second & 23.8 & 25.8 & 27.8 \\
Third & 27.8 & 30.2 & 42.9 \\
\hline
\end{tabular}

Measuring Wage, Earnings, and Productivity Gaps We measure the gender wage ratio as the average wages of females relative to average wages of males. Since people in our model differ in levels of education and experience, we compute the gender wage ratio within each education and experience level. We then use the distribution of experience across employed females to construct a weighted average of wage ratios for each education level. As a result, we obtain for each education level a gender wage ratio that controls for labor-market experience. Next, we use the distribution of education across employed females in order to construct an aggregate wage ratio that controls for differences in education and experience levels across genders. In this way, our statistics are readily comparable with the ones in the 
empirical literature (see, for instance, Blau and Kahn 1997 and 2000). In a similar fashion, we construct gender wage ratios for fertile females. Because wage differences in our matching framework are not due to productivity differences alone, we also compute productivity (e.g., output per hour of work) ratios in order to isolate the role of bargaining considerations in accounting for wage ratios. We measure the family wage ratio as average wages of females with children relative to average wages of females without children. In this computation we adjust for experience and education levels using the appropriate distributions in order to aggregate these ratios across categories. Finally, we also compute gender and family earnings ratios using a similar procedure.

Table 9 reports wage, productivity, and earnings ratios in our benchmark economy. Notice that the benchmark economy reproduces the target for the gender wage ratio which is 0.81. The statistic on the family wage ratio indicates that fertile females with children are paid, on average, 11 percent less than fertile females without children (after adjusting for differences in education and experience). Because productivity and wage ratios are quite similar, bargaining is not affecting much the magnitude of wage ratios. ${ }^{13}$ Earnings ratios are substantially lower than wage ratios since in our economy females with children work less hours than males (due to the time cost of children $\tau$ ).

Table 10 presents wage, productivity, and earnings ratios by education categories. Again, wage and productivity ratios tend to be similar. Surprisingly, the gender and family gaps are higher for females with the lowest and the highest education levels than for females in the intermediate educational group (even though the fertility rate is monotonically decreasing

\footnotetext{
${ }^{13}$ This is a consequence of our calibration of the bargaining power of workers, $\varepsilon$, that gives a large share of output to workers.
} 
Table 9: Gender and Family Ratios: Fertile Females

\begin{tabular}{lcc}
\hline & Gender Ratio & Family Ratio \\
\hline Wage & 0.81 & 0.89 \\
Productivity & 0.82 & 0.89 \\
Earnings & 0.68 & 0.70 \\
\hline
\end{tabular}

Table 10: Gender and Family Ratios by Education: Fertile Females

\begin{tabular}{lccc}
\hline & Edu1 & Edu2 & Edu3 \\
\hline Gender Ratio: & & & \\
Wage & 0.81 & 0.80 & 0.82 \\
Productivity & 0.82 & 0.80 & 0.82 \\
Earnings & 0.70 & 0.65 & 0.70 \\
\hline Family Ratio: & & & \\
Wage & 0.88 & 0.88 & 0.91 \\
Productivity & 0.89 & 0.88 & 0.90 \\
Earnings & 0.69 & 0.66 & 0.74 \\
\hline
\end{tabular}

with education). This result is intuitive once we notice that females with children are less likely to work if they have a low rather than a middle-education level, and that those working are self-selected among the ones with high levels of tenure capital. This selection effect can outweigh the decrease in productivity associated with children $\left(\omega_{\text {family }}\right)$ when differences in fertility rates are small.

Specific Human Capital and Wage/Productivity Gaps In our model economy, females are less productive than males for three reasons: (1) there is an exogenous gender productivity gap $\omega_{\text {gender }}$; $(2)$ each child reduces the labor productivity of a female by an amount $\omega_{\text {family }}$; and (3) females are likely to accumulate less specific capital than males, and this may be true even after controlling for differences in experience. To understand the 
last observation, the reader should bear in mind that females may interrupt their career (by permanently separating from their job) in order to enjoy staying at home with their children. Permanent separations can be costly since we assume that all accumulated specific (tenure) capital is lost upon separation. Females, of course, can enjoy staying at home with children by taking a leave and avoid a career interruption. But, leaves are costly in our model. In fact, females that take leaves in our benchmark economy make, on average, a substantial payment to their employers, as reported above. As a result, it should not be surprising that a substantial fraction of females permanently separate from their jobs after giving birth (see Table 6). Since females are more likely to separate from their jobs than males, they are also less likely to accumulate specific human capital. If this effect holds for people with the same labor-market experience, then the gender productivity gap will be higher than in a world with no specific human capital. A similar reasoning indicates that females with children are less likely to accumulate tenure capital than females without children, and that this effect could translate into the family productivity gap.

Our benchmark economy was calibrated to reproduce the gender and family wage gaps. We can thus use our model to ask whether specific capital can account for the gender and family wage gaps. We find that specific human capital plays a minor role in accounting for the wage gaps. To illustrate this result, we calculate exogenous productivity gender and wage ratios as follows: ${ }^{14}$

- Exogenous gender wage ratio $\left(1-\omega_{\text {gender }}\right)\left(1-\bar{b} \omega_{\text {family }}\right)$,

\footnotetext{
${ }^{14} \mathrm{We}$ refer to these gaps as exogenous since they are given by the parameters $\omega_{\text {gender }}$ and $\omega_{\text {family }}$. The calculations are a rough approximation because we are considering average (and thus aggregate) fertility rates. A more precise procedure would be to compute wage gaps subtracting actual specific capital and then aggregating across females.
} 
- Exogenous family wage ratio $\left(1-\bar{b} \omega_{\text {family }}\right)$,

where $\bar{b}$ is the fertility rate. We compute these exogenous wage ratios for each educational category using the fertility rate of each group. Table 11 compares the exogenous productivity ratios with the productivity ratios in our benchmark economy by education level.

Table 11: Productivity Ratios: Fertile Females

\begin{tabular}{ccccc}
\hline & Aggregate & Edu1 & Edu2 & Edu3 \\
\hline Gender ratio: & & & & \\
Benchmark & 0.82 & 0.82 & 0.80 & 0.82 \\
Exogenous & 0.80 & 0.78 & 0.79 & 0.82 \\
\hline & & & & \\
\hline Family ratio: & & & & \\
Benchmark & 0.89 & 0.89 & 0.88 & 0.90 \\
Exogenous & 0.90 & 0.89 & 0.90 & 0.93 \\
\hline
\end{tabular}

A striking observation from Table 11 is that the gap for fertile females in the benchmark economy is only 1 percentage point higher than the exogenous family gap; that is, in the absence of the exogenous family gap in the model (i.e., $\omega_{\text {family }}=0$ ), fertile females with children would have a productivity slightly lower than fertile females without children with the same experience and education. ${ }^{15}$ This striking result is a consequence of a selection mechanism: since labor-market and fertility decisions are endogenous in the model, mothers are self-selected from the group of females with low tenure capital, and thus permanent separations have a small impact on human capital. In Erosa, et al. (2002) we considered a decision-theoretic framework that abstracted from the demand side of the labor market (job creation) and temporary separations between the worker and the job. In that framework,

\footnotetext{
${ }^{15}$ Moreover, the endogenous productivity gap generated by the model has an upper bound of 3 percentage points for females of high education as reported in Table 11.
} 
we also found that tenure capital is not important for understanding the gender wage gap. This finding is robust to the introduction of general equilibrium because the value of tenure capital is internalized by the parties in the job match. As a result, females with high tenure capital are less likely to break job matches than females with low tenure capital.

Our result contradicts the hypothesis that human capital losses (due to job separations) are responsible for the observed family gap between women with and without children (see, Waldfogel, 1998b, and references therein). Albrecht, et al. (1999) and Phipps, et al. (2001) present some indirect evidence that supports our result. The specific human capital hypothesis implies that people who take time off on parental leave (that is, come back to the same job after the leave) should not face substantial changes in their wages after the leave, and this should hold for both men and women. Using Swedish data, Albrecht, et al. (1999) find that after taking a parental leave, women do not face substantial reductions in wages while men do. ${ }^{16}$ Moreover, Phipps, et al. (2001) report that accounting for time out of work for parental leave reduces the "ever-having-a-child" penalty by only 3 percentage points, using Canadian data where "ever having a child" implies a reduction in wages of 13 percentage points on average.

A careful look at Table 11 reveals two other relevant observations that at first may seem puzzling. For females of low education, the benchmark model generates a gender gap that is smaller than the exogenous gender gap and a family gap equal to the exogenous family gap. That is, tenure capital makes no difference for the family gap while it makes a negative difference for the gender gap. ${ }^{17}$ For females of high education, the result is reversed; the

\footnotetext{
${ }^{16}$ Fathers take relatively more parental leaves in Sweden than in other countries.

${ }^{17}$ To put it in another way, if there is no exogenous gender gap in the model (i.e., $\omega_{\text {gender }}=0$ ), females of
} 
benchmark model generates a gender gap similar to the exogenous gap, and a family gap larger than the exogenous gap. There is a unifying explanation for these observations that is related to the selection mechanism discussed before. Females of low education are rarely at work relative to the same group of males (the employment-to-population ratio is 0.49 for females and 0.84 for males), and the females working are self-selected among the ones with high tenure capital. The selection effect implies that these females have higher tenure capital than males with the same experience and education, leading to a decrease of the gender gap relative to the exogenous gap. At the same time, the selection effect is so important for this group of females that there is almost no difference between the tenure capital of females with and without children (they tend to be high-tenure females regardless of whether they have children or not). Females of high education level have the same employment level as males, and therefore the selection effect is small, leading to similar gender gaps. Since the selection effect is not important for this group, females with children tend to have less tenure capital than females without children.

\section{Mandatory Leaves}

In this section, we consider an economy with an institutional arrangement that entitles females to take maternity leaves after giving birth. Our goal is to study the aggregate and distributional impact of mandatory parental leaves on employment, labor-market turnover, fertility, wages, and welfare.

low education would have 4 percentage points higher productivity than males with the same experience and education. 


\subsection{The Economy with Mandatory Leaves}

We assume that females are entitled to take a leave of $\bar{e}$ periods after giving birth. Since we consider experiments where mandatory leaves are unpaid as well as paid, we keep the notation as general as possible. If leaves are paid, we assume that employers do not pay the benefits that females are entitled to, but face a $\operatorname{cost} C$ of the leave. Mandatory paid leaves are financed through a tax, collected on the labor income of all employed people regardless of gender. We assume that females on leave receive a benefit equal to a fraction $\theta$ of the last wage (when leaves are unpaid we set $\theta=0$, and the tax rate on labor income $\tau=0$ ). Mandatory-leave policies in O.E.C.D. countries resemble the institutional arrangement just described. ${ }^{18}$

We assume that females can only collect benefits when they are attached to a job. In particular, a female cannot reject a job offer and collect benefits (saving the employer from incurring the cost of a leave). The decision problem of a fertile female in this setting involves a new state variable $e$, denoting the number of periods of leave a female is entitled to. When a female gives birth, $e$ is set at $\bar{e}$, the maximum number of periods of leave entitlements prescribed by the law. If the female takes a leave, next period $e$ is set at $e^{\prime}=\max \{e-1,0\}$. If she does not take a leave, $e$ is set at 0 (for convenience we denote this state as $e_{0}$ ).

We do not rule out the possibility of voluntary leaves. That is, females can negotiate with their employer, period by period, for a longer leave than the one guaranteed by the law.

\footnotetext{
${ }^{18}$ Ruhm (1998, Table 1, page 297) reports the institutional arrangement of mandatory leaves for a set of European countries. The entitlements in Europe are financed through general payroll taxes imposed by the Government, with replacement wage rates that go from 60 percent in Greece to 100 percent in Germany, and duration ranging from 14 weeks in Ireland to 64 weeks in Sweden. The mandatory entitlement in the U.S. since 1993 allows for 12 weeks of unpaid leave.
} 
When a female is not entitled to take a mandatory leave $\left(e=e_{0}\right)$, the functions defining the value of accept $A$, leave $L$, and reject $R$ are the same as the ones described under the voluntary leaves arrangement. The same applies to the value of a job and the bargaining equation defining wages when working and on a (voluntary) leave. When a female is entitled to a leave, the equation defining the wage of a mandatory paid leave is given by

$$
w_{l}^{f}(d, h, n, v, e)=\theta w^{f}\left(d_{0}, h, n-1, v, e_{0}\right) .
$$

The above recursive representation of the benefit of a paid leave has the advantage that we do not need to carry as a state variable the last wage received before taking a leave. We approximate this wage by the wage paid to a female in state $\left(d_{0}, h, n-1, v, e_{0}\right)$. The implicit assumptions are that the last time (or period) the female was working she had $n-1$ children, could not enjoy the value of staying at home with a child $d=d_{0}$, and had no entitlements. ${ }^{19}$

We allow for the possibility of side payments between the employer and the worker so that they both agree on whether to work, temporarily separate, or break the match. In particular, if the surplus is maximized when the match is destroyed, the firm will compensate the female for rejecting the job and losing the benefit entitlements. The bargaining equation determining the side payment, which we denote as $w_{r}$, satisfies

$$
R(s)+w_{r}(s)-L(s)=\frac{\varepsilon}{1-\varepsilon}\left[-w_{r}(s)-J_{l}(s)\right]
$$

\footnotetext{
${ }^{19}$ Note that the above formula is an approximation (although a fairly accurate one in most cases) because it may occur that a female has two children without coming back to work while keeping the job match. Also, it may happen that the human capital may have changed after the last time a female worked. It is also worth emphasizing that because $d=d_{0}$ the benefit of a paid leave is independent of the current realization of $v$.
} 
where we use the compact notation $s=(d, h, n, v, e)$ to denote the state of the worker. When a female is entitled to a leave, the threat point is given by the value of a leave (which is higher than the value of reject). If the worker takes a leave, the value of a job for the firm is equal to $J_{l}$. If $J_{l}$ is too negative, the employer may be willing to pay $w_{r}$ to the worker so that the female rejects and obtains $R+w_{r}>L$, while the employer obtains $-w_{r}>-J_{l}(s)$. When a female is entitled to a leave, the value of a job is thus given by

$$
J^{f}(s)=\max \left\{J_{a}^{f}(s), J_{l}^{f}(s),-w_{r}(s)\right\}
$$

which can be negative. Since employers are forward looking, they take this possibility into account when negotiating wages with fertile females. It is also worth noting that if the surplus is maximized, when a female decides to work, and the worker is entitled to a leave, then the employer pays the worker a wage in order to induce the female to work. In this case, the threat point of the worker is given by the value of taking a leave since, in this state, the value of a leave weakly dominates the value of reject for the worker. Thus, the following equation is satisfied

$$
A^{f}(s)-L^{f}(s)=\frac{\varepsilon}{1-\varepsilon}\left[J_{a}(s)-J_{l}(s)\right] .
$$

The previous discussion makes it clear that bargaining, together with the possibility of side payments, implies that the surplus of a match is always maximized. However, mandatory paid leaves may not be efficient from the viewpoint of a society. When leaves are centrally financed through tax revenues from the government, the benefits paid to females on leave may subsidize inefficient matches. To put it simply, a match that would be destroyed in the 
absence of leave entitlements may not be destroyed because the worker may require a large side payment $w_{r}$ in order to give up the leave entitlement.

\subsection{Quantitative Experiments}

We study the effects of mandatory-leave policies in our benchmark economy. To this end, we consider the effects of unpaid mandatory leaves of 1 model period (three months), which corresponds to the institutional arrangement in the U.S. after the passage of the 1993 F.M.L.A. We also consider "European-style" mandatory leave policies involving 1 and 2 periods of fully paid leaves (e.g., leaves that pay 100 percent of the wage of a female up to 3 or 6 months after giving birth). In addition, we document the effects of very long (up to a year) unpaid and paid leaves since several countries, in particular Canada, have recently moved to leave entitlements of this long duration. We find that a one-period unpaid mandatory-leave policy has a very small impact on aggregate behavior in the economy, in particular on employment, consistent with the evidence in Ruhm (1998) for European leaves of short duration and Kleirman and Leibowitz (1999) for the U.S. Other more generous policies have similar aggregate effects. However, we find important changes in fertility and employment behavior across educational groups, as well as substantive (redistributive) effects on steady-state welfare. The introduction of parental leave policies leads to substantial aggregate (steady-state) welfare losses for newly-born individuals because these policies subsidize inefficient matches and encourage too much leave taking by fertile females. 
Fertility Rates Mandatory leave entitlements have an impact on fertility rates. This result questions the often-used assumption in the empirical wage literature on the exogeneity of fertility rates. It is interesting that the response of the fertility rate to the introduction of mandatory leaves differs across educational categories (see Table 12). While the fertility rate of females with low education decreases monotonically with the generosity of entitlements, fertility rates of females in the second and third education category increase with entitlements. In particular, the fertility rate of females with high education increases from 1.55 under unpaid leaves to 1.76 under 2 period paid leaves. For all educational categories, fertility rates are the lowest in the benchmark economy (voluntary leaves only).

Table 12: Fertility Rates by Education

\begin{tabular}{lcccc}
\hline & Aggregate & Edu1 & Edu2 & Edu3 \\
\hline Benchmark & 2.11 & 2.43 & 2.24 & 1.54 \\
Unpaid 1 & 2.14 & 2.47 & 2.27 & 1.55 \\
Unpaid 4 & 2.15 & 2.47 & 2.30 & 1.57 \\
Paid 1 & 2.18 & 2.46 & 2.30 & 1.69 \\
Paid 2 & 2.20 & 2.45 & 2.32 & 1.76 \\
Paid 4 & 2.23 & 2.43 & 2.33 & 1.85 \\
\hline
\end{tabular}

Employment The employment ratio of mothers with infants increases substantially with the generosity of the entitlements, specially for the first two educational categories (see Table 13). Consequently, employment of fertile females also increases with the generosity of entitlements in the case of females at the lowest educational category. For this educational group, when mandatory leaves are paid, the employment level of mothers with infants is higher than that of fertile females. This finding suggests that mothers with low education 
postpone breaking the job match until the end of their leave entitlement. The employment of fertile females at the two highest education categories decreases with the generosity of leaves. This decrease of employment is due to the increase in the fertility rates of these females. Table 14 shows that leaves, as a fraction of female employment, increase for females of all education levels. Surprisingly, mandatory leaves have a very small impact on the employment of males, which means that these policies have a small impact on the decision of firms to post vacancies. This result may be explained by the low tax rate needed to finance parental leave policies (the tax rate on labor income in the economy with two-period leaves is equal to 1.1 percent).

Table 13: Employment-to-Population Ratios by Education

\begin{tabular}{l|ccc|ccc}
\hline & \multicolumn{3}{|c|}{ Fertile } & \multicolumn{3}{c}{ Mothers with Infants } \\
& Edu1 & Edu2 & Edu3 & Edu1 & Edu2 & Edu3 \\
\hline Benchmark & 0.49 & 0.72 & 0.84 & 0.26 & 0.48 & 0.77 \\
Unpaid 1 & 0.48 & 0.72 & 0.84 & 0.27 & 0.55 & 0.81 \\
Unpaid 4 & 0.48 & 0.71 & 0.83 & 0.27 & 0.59 & 0.81 \\
Paid 1 & 0.51 & 0.71 & 0.83 & 0.55 & 0.66 & 0.81 \\
Paid 2 & 0.52 & 0.69 & 0.83 & 0.64 & 0.71 & 0.82 \\
Paid 4 & 0.53 & 0.69 & 0.83 & 0.72 & 0.76 & 0.83 \\
\hline
\end{tabular}

Table 14: Fraction of Leaves (\%)*

\begin{tabular}{lcccc}
\hline & Aggregate & Edu1 & Edu2 & Edu3 \\
\hline Benchmark & 0.3 & 0.2 & 0.5 & 0.3 \\
Unpaid 1 & 0.6 & 0.3 & 0.9 & 0.5 \\
Unpaid 4 & 0.7 & 0.4 & 1.3 & 0.6 \\
Paid 1 & 3.0 & 4.0 & 3.1 & 2.0 \\
Paid 2 & 4.5 & 5.7 & 4.6 & 3.0 \\
Paid 4 & 6.6 & 8.2 & 6.8 & 4.8 \\
\hline
\end{tabular}

* Relative to female employment. 
Employment vs. Work Parental-leave policies introduce a distinction between employment and work since these policies encourage females to take leaves (see, for instance, Klerman and Leibowitz (1994) for a detailed documentation of the employment/work distinction in the data). This distinction may be relevant for wages of females if more work leads to more human capital accumulation on the job (see Erosa, et al. (2005) for a quantitative assessment of this channel in the U.S. economy). Therefore, it is of interest to quantify the impact of mandatory leave policies on the working decision of females. Table 15 reports the working and employment-to-population ratios for fertile females and for mothers with infants. The Table shows that mandatory leave policies increase employment of females and mothers with infants due to the increase in leave taking by these females. Whereas in the benchmark economy 44 percent of mothers with infants are employed and 41 percent are working, in the economy with six-months-paid mandatory leaves (Paid 2) 71 percent of mothers with infants are employed, but only 22 percent are working. Notice that, relative to the outcome in the benchmark economy, one-quarter-unpaid mandatory leaves (Unpaid 1) (similar to the leave entitlements in the U.S. economy since 1993) raise the working-topopulation ratio of mothers with infants although the quantitative effect is relatively small. We conclude that mandatory leaves lead to greater employment by females due to greater leave taking.

Time Spent at Home with Children An important question is whether mandatory leaves increase the time that mothers spend at home with children or not. Proponents of mandatory leaves argue that these policies can benefit the health of children by increasing the 
Table 15: Employment/Working to Population Ratios

\begin{tabular}{l|cc|cc}
\hline & \multicolumn{2}{|c|}{ Fertile Females } & \multicolumn{2}{c}{ Mothers with Infants } \\
& Employment & Working & Employment & Working \\
\hline Benchmark & 66.4 & 66.0 & 44.1 & 40.7 \\
Unpaid 1 & 66.0 & 65.3 & 47.8 & 41.3 \\
Unpaid 4 & 65.6 & 64.7 & 49.2 & 40.6 \\
Paid 1 & 66.6 & 63.0 & 64.4 & 29.5 \\
Paid 2 & 66.4 & 61.0 & 70.6 & 21.6 \\
Paid 4 & 66.6 & 58.6 & 76.1 & 13.2 \\
\hline
\end{tabular}

amount of time that mothers spend at home with their children (by facilitating breast feeding and by enhancing cognitive development as discussed in Ruhm (2000) and the references therein). Ruhm (2000) finds some empirical support for a positive impact of parental leave policies on children's health in Europe. In particular, using a regression approach, Rhum finds that a 10-week extension of mandatory leaves is predicted to decrease infant mortality between 1 and 2 percent.

We can use our theory to quantify the effect of mandatory leaves on the time that mothers spend at home with children. Theoretically, mandatory leaves have an ambiguous effect on the time mothers spend with their children: mandatory leaves may induce some mothers to take longer leaves but at the same time may also induce some other mothers to take a short leave instead of being out of employment for a long period. In order to investigate how mandatory leaves affect the time that mothers spend with their children, we first look at the labor decisions of mothers after giving birth. In particular, Table 16 reports the fraction of females who accept, reject, and take a leave after having a child. Unpaid leaves have a modest impact on the fraction of females who stay at home after having a child, 
which is 62 percent in the benchmark economy and 61 and 62 percent in the economies with 1-quarter-unpaid and 4-quarter-unpaid mandates. Paid leaves have a substantial impact on the fraction of females who stay at home after having a child, which increases up to 96 percent in the economy with 4-quarters-paid leave mandates.

Table 16: Labor-Market Decisions of Females Giving Birth (\%)

\begin{tabular}{lcccccc}
\hline & Benchmark & Unpaid 1 & Unpaid 4 & Paid 1 & Paid 2 & Paid 4 \\
\hline Accept & 38 & 39 & 38 & 15 & 8 & 4 \\
Reject & 51 & 39 & 37 & 0 & 0 & 0 \\
Leave & 11 & 22 & 25 & 85 & 92 & 96 \\
\hline
\end{tabular}

We next look at the average time that females spend at home with their children conditional on females taking a leave or rejecting a job offer after birth. Table 17 shows that the duration of leaves increases with the length of the entitlement, and that paid leaves are longer than unpaid leaves of the same length of entitlement. As in the benchmark economy with voluntary leaves, the length of a leave decreases with the education attaintment of females in all the economies.

Table 17: Duration Leaves by Education (quarters)

\begin{tabular}{lcccc}
\hline & Average & Edu1 & Edu2 & Edu3 \\
\hline Benchmark & 1.74 & 2.10 & 1.92 & 1.34 \\
Unpaid 1 & 1.45 & 1.54 & 1.52 & 1.31 \\
Unpaid 4 & 1.88 & 2.09 & 2.06 & 1.50 \\
Paid 1 & 1.90 & 1.98 & 1.89 & 1.70 \\
Paid 2 & 2.78 & 2.94 & 2.77 & 2.55 \\
Paid 4 & 4.59 & 4.91 & 4.59 & 4.17 \\
\hline
\end{tabular}

Table 17 also shows that leaves are of longer duration in the benchmark economy than in the economy with 1-quarter-unpaid mandatory leaves. In order to understand this finding, 
we report in Table 18 the duration distribution of leaves in each of the economies. The introduction of 1-quarter-unpaid mandatory leaves leads to the elimination of leaves of 3 or more quarters, which explains the reduction in the average length of a leave.

Table 18: Duration Distribution of Leaves

\begin{tabular}{lcccccc}
\hline & Benchmark & Unpaid 1 & Unpaid 4 & Paid 1 & Paid 2 & Paid 4 \\
\hline Average (quarters) & 1.7 & 1.4 & 1.8 & 1.9 & 2.7 & 4.6 \\
Distribution (\%): & & & & & & \\
$\quad 1$ quarter & 60 & 55 & 53 & 17 & 10 & 6 \\
2 quarters & 22 & 44 & 23 & 78 & 15 & 6 \\
3 quarters & 10 & 1 & 12 & 3 & 69 & 9 \\
4 quarters & 4 & 0 & 7 & 0 & 2 & 12 \\
$\quad$ More than a year & 4 & 0 & 5 & 0 & 0 & 63 \\
\hline
\end{tabular}

When leaves are unpaid, some females prefer to be non-employed after having a child instead of being on leave. In this case, it is interesting to quantify the impact of the length of the entitlement on the duration of the non-employment spell due to childbirth. Table 19 reports the distribution of the duration of non-employment spells at the birth of a child. ${ }^{20}$ Notice that mandatory leaves increase the fraction of females that stay non-employed for more than a year, increasing the average duration of a non-employment spell due to births.

We conclude that mandatory leaves decrease the average time that a mother spends at home after having a child (see Table 20). Notice that unpaid leaves induce mothers to spend more time with their children than paid leaves of the same length of entitlement. When leaves are unpaid, some females prefer to be non-employed during a long period instead of being on leave for a short period. Benefits induce females to be attached to their jobs and, thus, they spend less time at home with their children.

\footnotetext{
${ }^{20}$ The column of data in Table 19 comes from calculations in Erosa, et al. (2005) using the NLSY79.
} 
Table 19: Duration of Non-Employment Spells at Childbirth

\begin{tabular}{lcccc}
\hline & Data & Benchmark & Unpaid 1 & Unpaid 4 \\
\hline Average (quarters) & 8 & 11.3 & 13.1 & 13.4 \\
Distribution (\%): & & & & \\
1 quarter & 23 & 18 & 14 & 13 \\
2 quarters & 10 & 12 & 10 & 9 \\
3 quarters & 9 & 9 & 8 & 8 \\
4 quarters & 7 & 7 & 7 & 6 \\
More than a year & 51 & 54 & 60 & 64 \\
\hline
\end{tabular}

Table 20: Average Time Mothers Spend at Home After Birth

\begin{tabular}{ccccccc}
\hline & Benchmark & Unpaid 1 & Unpaid 4 & Paid 1 & Paid 2 & Paid 4 \\
\hline (quarters) & 9.6 & 9.2 & 9.3 & 7.7 & 8.0 & 9.3 \\
\hline
\end{tabular}

Wage Gaps A striking finding of the voluntary-leaves model is that when fertility and labor-market decisions interact, labor turnover causes small losses of specific human capital. Therefore, mandatory leave policies in our environment can only have a small impact on the wage gaps.

In Table 21 we report the gender and family wage gaps for the economies under study. The table shows a reduction of the family gap and an increase in the gender gap as parentalleave policies become more generous. However, changes are quantitatively small (less than a percentage point in both cases). This result should not be surprising given our previous finding that specific capital did not play a significant role in accounting for the gender and family wage gaps in the benchmark economy. Therefore, promoting job attachment among recent mothers does not increase the specific capital of employed females because mothers in the economy with voluntary leaves lose, on average, little specific capital in the first place. 
In fact, the increase in female employment due to parental leaves implies that the pool of working females has, on average, lower tenure or specific capital (controlling for experience). The increase in the fertility rate among females of the two highest educational categories also contributes to the increase in the gender gap. Mandatory entitlements imply a redistribution from non-mothers to mothers, which reduces the family wage gap.

Table 21: Fertile Female Wage Ratios

\begin{tabular}{lcccc}
\hline Gender Ratio & & & & \\
& Aggregate & Edu1 & Edu2 & Edu3 \\
\hline Benchmark & 0.8092 & 0.81 & 0.80 & 0.82 \\
Unpaid 1 & 0.8095 & 0.81 & 0.80 & 0.82 \\
Paid 1 & 0.8069 & 0.81 & 0.80 & 0.81 \\
Paid 2 & 0.8052 & 0.81 & 0.80 & 0.81 \\
\hline \multicolumn{5}{c}{} \\
Family Ratio & & & & \\
& Aggregate & Edu1 & Edu2 & Edu3 \\
\hline Benchmark & 0.8879 & 0.88 & 0.88 & 0.90 \\
Unpaid 1 & 0.8936 & 0.89 & 0.88 & 0.91 \\
Paid 1 & 0.8906 & 0.88 & 0.88 & 0.91 \\
Paid 2 & 0.8944 & 0.89 & 0.89 & 0.91 \\
\hline
\end{tabular}

Welfare The welfare implications of parental-leave policies in our model differ substantially across gender and educational categories. In our model, the welfare of males falls relative to that of females because males pay taxes without benefiting from leave policies. The welfare gains of highly educated females are smaller than the welfare gains of poorly educated females. We compute the welfare cost of mandatory leave policies as the amount of consumption required by a newborn individual to be indifferent between living a lifetime in the benchmark economy and in the mandatory-leaves economy being considered. Note 
that we compute a constant annual consumption compensation which is applied for 45 years $(45 \times 4$ periods). The results are reported in Table 22 for the aggregate of males and females, and in Table 23 for individuals by education. It should not be surprising that mandatory leaves lead to aggregate welfare losses: by subsidizing leave taking, these policies distort the decision of keeping vs. destroying a match and the decision of whether to work or take a leave. Females gain substantially with generous policies, but this benefit occurs at at the expense of a reduction in the welfare of males. The fact that parental-leave policies have sizeable welfare-effects of opposite sign across genders suggests that these policies should affect resource allocation within the household. Extending our framework to model household decisions is a non-trivial task that is left for future research.

Table 22: Welfare of Newborns*

\begin{tabular}{l|cc}
\hline & Males & Females \\
\hline Benchmark & 0.0 & 0.0 \\
Unpaid 1 & -0.08 & -0.02 \\
Paid 1 & -0.47 & 0.16 \\
Paid 2 & -0.68 & 0.33 \\
\hline
\end{tabular}

*Annual consumption compensation for 45 years. Numbers expressed as percentage of annual per-capita GDP of the benchmark economy.

\section{Conclusions}

This paper builds a quantitative theory of labor-market and fertility decisions that is successful in matching U.S. data regarding employment, wages, and fertility rates both at the aggregate level and across gender and education groups. We build on the labor-market the- 
Table 23: Welfare of Newborns by Education*

\begin{tabular}{l|ccc|ccc}
\hline & \multicolumn{3}{|c|}{ Female } & \multicolumn{3}{c}{ Male } \\
& Edu1 & Edu2 & Edu3 & Edu1 & Edu2 & Edu3 \\
\hline Benchmark & 0.0 & 0.0 & 0.0 & 0.0 & 0.0 & 0.0 \\
Unpaid 1 & -0.04 & -0.01 & -0.05 & -0.06 & -0.07 & -0.12 \\
Paid 1 & 0.23 & 0.24 & 0.01 & -0.32 & -0.43 & -0.72 \\
Paid 2 & 0.44 & 0.45 & 0.06 & -0.47 & -0.61 & -1.01 \\
*Annual consumption compensation for 45 years. Numbers ex- \\
pressed as percentage of annual per capita GDP of the benchmark \\
economy.
\end{tabular}

ory of Mortensen and Pissarides (1994). We extend this basic framework in three dimensions: First, we model male and female workers, where females make fertility decisions. Second, we model human-capital accumulation on the job in the form of general and specific human capital. Third, we model temporary job separations of female workers due to childbirth. We consider two institutional arrangements for temporary job separations: voluntary and mandatory leaves. We use our theory to quantify the impact of mandatory-leave entitlements on fertility, employment, and wages in the aggregate and across education and gender groups.

We find that mandatory-leave policies lead to substantial redistributions across people in terms of steady-state welfare and changes in fertility and employment ratios. Mandatory leaves have often been motivated by the importance of the job attachment of females in the preservation of valuable specific human capital. However, we find that mandatory leave policies in our model have small effects on the wages of females. Leave policies could lead to wage gains for females if they encourage more work. (See for instance Mincer and Polachek, 1974 and Erosa, et al., 2005.) In our model, generous mandatory policies reduce the working- 
to-population ratios of mothers with young children. Nonetheless, even if these policies had a positive impact on the amount of work of females, it is unclear how these policies would compare to other policies aimed at increasing the work time of females such as child-care services, flexible work schedules, among others. Mandatory-leave policies are also motivated by the positive impact that more home-dedication time of mothers could have on their children. In our model, we find that leave policies have a small effect (in some cases negative) on the amount of time that females spend at home with their children.

Our work can be extended in a number of dimensions. It would be interesting to consider other hypotheses regarding the effects of fertility on labor outcomes, such as, the effort made in the workplace by mothers, as suggested by Becker (1985), and selection of women among job types. Private information on people's preferences towards family leaves may lead to an under-provision of parental leaves in a voluntary environment; therefore, it would be relevant to consider a framework with asymmetric information about people's preferences regarding the value of time spent with children, and how this positive role for parental-leave policies interact with the negative effects in the labor market. Finally, our framework is suitable for studying parental-leave policies in conjunction with other labor-market institutions that may affect the female labor supply in important ways (such as the availability of part-time jobs, child-care policies, firing costs and other employment-protection policies). 


\section{References}

[1] Aiyagari, Rao, Jeremy Greenwood, and Nezih Guner. 2000. "On the State of the Union," Journal of Political Economy 108(2): 213-44.

[2] Albrecht, James, Per-Anders Edin, Marianne Sundstrom, and Susan Vroman. 1999. "Career Interruptions and Subsequent Earnings: A Reexamination Using Sweedish Data," Journal of Human Resources 34(2): 294-311.

[3] Angrist, Joshua D. and William N. Evans. 1998. "Children and Their Parents' Labor Supply: Evidence from Variation in Family Size," American Economic Review 88(3): 450-477.

[4] Andolfatto, David. 1996. "Business Cycles and Labor-Market Search," American Economic Review 86(1):112-32.

[5] Bachu, Amara and Martin O'Connell. 2000. Fertility of American Women: June 1998. Current Population Reports. P20-526. U.S. Census Bureau.

[6] Becker, Gary S. 1985. "Human Capital, Effort, and the Sexual Division of Labor," Journal of Labor Economics 3: S33-S38.

[7] Blanchard, Olivier and Peter Diamond. 1989. "The Beveridge Curve," Brookings Papers on Economic Activity (1): 1-76.

[8] Blau, Francine D. and Lawrence M. Kahn. 1992. "The Gender Earnings Gap: Learning from International Comparisons," American Economic Review 82(2): 533-38.

[9] Blau, Francine D. and Lawrence M. Kahn. 1997. "Swimming Upstream: Trends in the Gender Wage Differential in the 1980's," Journal of Labor Economics 15(1): 1-42.

[10] Blau, Francine D. and Lawrence M. Kahn. 2000. "Gender differences in Pay," Journal of Economic Perspectives 14(4): 75-99.

[11] Blau, Francine D. 1998. "Trends in the Well-Being of American Women, 1970-1995," Journal of Economic Literature 26: 112-65.

[12] Caucutt, Elizabeth, Nezih Guner, and John Knowles. 2002. "Why Do Women Wait? Matching, Wage Inequality, and the Incentives of Delay," Review of Economic Dynamics 5: 815-55. 
[13] Da-Rocha, José María and Luisa Fuster. 2005. "Why Are Fertility Rates and Female Employment Ratios Positively Correlated Across O.E.C.D. Countries?," mimeo, University of Toronto. (Forthcoming in International Economic Review.)

[14] Economic Report of the President. U.S. Government Printing Office. Washington. Various Issues.

[15] Erosa, Andrés, Luisa Fuster, and Diego Restuccia. 2002. "Fertility Decisions and Gender in Labor Turnover, Employment, and Wages," Review of Economic Dynamics 5: 856891.

[16] Erosa, Andrés, Luisa Fuster, and Diego Restuccia. 2005. "A Quantitative Theory of the Gender Gap in Wages," mimeo, University of Toronto.

[17] Fernández, Raquel, and Richard Rogerson. 2001. "Sorting and Inequality," Quarterly Journal of Economics 116(4): 1305-1341.

[18] Haveman, Robert and Barbara Wolfe. 1995. "The Determinants of Children's Attainments: A Review of Methods and Findings," Journal of Economic Literature 33: 18291878.

[19] Klerman, Jacob A., and Arleen Leibowitz. 1999. "Job Continuity Among New Mothers," Demography 36(2): 145-155.

[20] Klerman, Jacob A. and Arleen Leibowitz. 1994. "The Work-Employment Distinction Among New Mothers," Journal of Human Resources 29(2): 277-303.

[21] Ljungqvist, Lars and Thomas Sargent. 1998. "The European Unemployment Dilemma," Journal of Political Economy 106(3): 514-550.

[22] Mincer, Jacob and Solomon Polachek. 1974. "Family Investments in Human Capital: Earnings of Women." Journal of Political Economy 82: S76-S108.

[23] Mortensen, Dale, and Christopher Pissarides. 1994. "Job Creation and Job Destruction in the Theory of Unemployment," Review of Economic Studies 61(3): 397-415.

[24] OECD. 1995. Employment Outlook. Chapter 5. Paris. July.

[25] Phipps, Shelley, Peter Burton, and Lynn Lethbridge. 2001. "In and Out of the Labour Market: Long-Term Income Consequences of Child-Related Interruptions to Women's Paid Work," Canadian Journal of Economics 34(2): 411-29. 
[26] Regalia, Ferdinando, and José-Víctor Ríos-Rull. 1999. "What Accounts for the Increase in the Number of Single Households?," mimeo, University of Pennsylvania.

[27] Royalty, Anne. 1998. "Job-to-Job and Job-to-Nonemployment Turnover by Gender and Education Level," Journal of Labor Economics 16(2): 392-443.

[28] Ruhm, Christopher J. 1998. "The Economic Consequences of Parental Leave Mandates: Lessons from Europe," Quarterly Journal of Economics 113: 285-317.

[29] Ruhm, Christopher J. 2000. "Parental Leave and Child Health," Journal of Health Economics 19: 931-960.

[30] Topel, Robert. 1991. "Specific Capital, Mobility, and Wages: Wages Rise with Job Seniority," Journal of Political Economy 99(1): 145-76.

[31] van Ours, Jan and Geert Ridder. 1992. "Vacancies and the Recruitment of New Employees," Journal of Labor Economics 10(2): 138-55.

[32] Waldfogel, Jane. 1998a. "The Family Gap for Young Women in the United States and Britain: Can Maternity Leave Make a Difference?" Journal of Labor Economics 16(3): 505-545.

[33] Waldfogel, Jane. 1998b. "Understanding the "Family Gap" in Pay for Women with Children," Journal of Economic Perspectives 12(1): 137-156.

[34] Wood, Robert, Mary Corcoran, and Paul Courant. 1993. "Pay Differences among the Highly Paid: The Male-Female Earnings Gap in Lawyers' Salaries," Journal of Labor Economics 11(3): 417-441. 